\title{
Highlighting the wider relevance of science centre evaluations: a reflection on the evaluation of a physics engagement programme
}

\section{Heather King, Emily Dawson and Rodolfo Leyva}

\begin{abstract}
This paper reflects on the evaluation of and findings from a nationwide programme of physics engagement activities hosted by 10 science centres across the UK. We discuss our findings indicating the affordances of the programme with reference to the wider literature in order to draw out elements of the project that may be useful for other science learning and engagement initiatives. In particular, we discuss findings that relate to contemporary research and policy interests around the engagement of girls in science, the key ages at which young people's views may best be influenced, the importance of explicating the nature of 'real-world' content and careers, and the value of collaborative partnerships.
\end{abstract}

Keywords

Public engagement with science and technology; Science centres and museums; Informal learning

In August 2014, the UK's Joint Council for Qualifications (JCQ) released data showing that only $4.4 \%$ of all A-Level students ${ }^{1}$ had taken physics that year [JCQ, 2014]. This percentage, though larger than the previous year, is part of an overall downward trend in the numbers of students pursuing physics in the UK, which the Institute of Physics (IoP) have dated from the early 1990s [IoP, 2014]. Indeed, concerns have been raised internationally regarding the numbers of students choosing to study physics at university and, subsequently, to enter physics-related careers [National Science Foundation, 2012; Smith, 2010; Ulriksen, Madsen and Holmegaard, 2010]. As a result, considerable efforts have been made in a number of countries to promote student uptake of the physical sciences [see for example Carpineti et al., 2006; Eratuuli and Sneider, 1990; GIREP, 2002]. In this paper we reflect on the evaluation of one specific, UK-based attempt to promote student interest in physics and the related physical sciences through a year-long programme of activities across 10 science centres.

The informal science education (ISE) sector, including science centres, museums, and other out-of-school learning environments, has long been positioned as a key player in supporting students to learn physics, enjoy physics, and develop a sense

\footnotetext{
${ }^{1}$ The qualifications for students (usually aged between 16 and 18) completing their pre-University education in England, Wales and Northern Ireland.
} 
of physics as something that they can do, and could continue to pursue in the future [Anderson and Nashon, 2007; Aroca and Silva, 2011; Eratuuli and Sneider, 1990; Nielsen, Nashon and Anderson, 2009]. It has been argued that the hands-on exhibits of science centres allow learners to engage with scientific phenomena in memorable ways while unique objects and displays presented in science museums provide the historical and social context to the everyday relevance of science [Bamberger and Tal, 2008; Dewitt and Hohenstein, 2010; Morris, 1990].

In contrast, many schools have limited resources for teaching aspects of science, and physics in particular [Woolhouse and Cochrane, 2010]. With few resources and often a limited ability to implement classroom experiments and practical activities, schools may have difficulty in inspiring students to continue their studies in the physical sciences. As Osborne and Collins [2000] have shown, participation in practical science activities is a key factor in fostering student interest, and thus prolonged engagement. It has therefore been argued that schools and ISE institutions ought to work collaboratively to provide a range of mutually enhancing learning experiences for students [Anderson and Nashon, 2007; Bell et al., 2009; Nielsen, Nashon and Anderson, 2009]. On the basis of these studies, it would seem that developing a science centre-based physics engagement programme, targeting schools and families, would be a good idea.

The role of evaluation in physics and ISE programmes
Given the sizeable efforts to recruit students to physics, it is unsurprising that the physics learning landscape has also been the site of much evaluation and research. At the same time, evaluations have become a core part of standard professional practice in ISE institutions [Hein, 1994; Sanchez-Mora, 2014] and are now largely embedded in the ISE sector [Lloyd et al., 2012; Phipps, 2010]. Evaluation practice in both physics education programmes and ISE may also have been influenced by the growing areas of work in programme evaluation, stakeholder evaluation and community participation evaluation which are on-going in fields as diverse as health care, community literacy and public policy, [Bledsoe and Graham, 2005; Brandon and Fukunaga, 2014; Reichborn-Kjennerud, 2014].

Programme or project evaluations can be useful in a number of ways. Evaluation is understood to be a valuable resource for benchmarking user experiences and informing their improvement. For example, the Stimulating Physics Network (SPN), established by the UK's Institute of Physics, aimed to offer school-based support for teachers. The evaluation of the Network found that participating teachers and their students did benefit from the resources on offer, with some forms of support being perceived to be more valuable than others [Babcock Research, 2011]. Evaluations are also seen as a method of institutional accountability, especially in relation to reports for funders or trustees. Indeed, key stakeholders, especially funders, are eager to know whether projects represent a worthwhile investment [King et al., 2015]. More broadly, ISE project or programme specific evaluations have provided data to inform numerous context-specific studies [see for example, Moussouri and Roussos, 2013; Storksdieck, Haley-Goldman and Jones, 2002]. Evaluations can also contribute to important methodological developments in ISE research [see for example, Nurse Rainbolt, Benfield and Loomis, 2012].

Although evaluation practice is now well established in physics and ISE practice, it is not without its challenges. One key problem is that the long-term effects of 
science learning and engagement initiatives, such as SPN, are much harder to evaluate than the immediate impact of one activity. In this way, it is difficult to identify relationships between participation in, for example, a physics engagement initiative, and the uptake of physics and entry into physics-related careers. It is even more difficult to claim causality. Attempts to claim impact are further complicated by often contradictory data. For instance, while the absolute numbers of students taking physics A-level has seen a small increase year on year between 2009 and 2014, the percentage of students taking physics compared to other subjects has dropped [IoP, 2014]. Furthermore, and as Smith [2010] has shown, the number of students opting to study physics at university in the UK between 1994 and 2009 has remained constant, unlike other science subjects where numbers have increased.

Our second concern with evaluation practice is to what extent those working in the field of physics and ISE are able to reap the benefits of the large number of evaluations that take place. With programmes, projects and participants' experiences being evaluated almost as a matter of routine, substantial information should be flowing from one project to the next, and from one institution to its neighbours. However, concerns have been raised over whether the potential learning developed in science engagement evaluations is ever fully realised or shared. For instance, a recent analysis found that visitor studies reports and evaluations in the field of ISE rarely linked their findings to other initiatives in the field, failed to explain their methodological choices, and appeared to be largely a-theoretical [Falk et al., 2012]. In other words, while a project team may benefit from an evaluation of its efforts, it can be hard for others to unpick the conclusions and generalise the findings to new settings.

In light of these concerns, we use this paper to reflect on the evaluation findings of Explore Your Universe (EYU) - a nationwide programme of physics engagement and learning activities hosted by 10 science centres across the UK between 2012 and 2013. In doing so we hope to offer an account of the evaluation process and moreover share some of the more widely relevant key findings to support field-wide learning. To some extent, our analyses blur the lines between evaluation and research, and in this way join a small but increasing number of studies that combine elements of both, such as the work of Luke and McCreedy [2012] and Yalowitz et al. [2013].

The evaluation context: the Explore Your Universe project
The Explore Your Universe (EYU) programme was developed collaboratively by the Science and Technology Facilities Council (STFC), a UK funding body that supports research in the physical sciences, and the UK Association for Science and Discovery Centres (ASDC), a network of science centres in the UK. The programme aimed to "inspire a new sense of excitement amongst young people around the physical sciences by sharing the amazing stories and technologies of STFC" [UK ASDC, 2011, p. 5]. The programme therefore focused on inspiring young people via family or school visits to science centres, with a view to supporting physics learning and student recruitment to the physical sciences. The EYU programme also sought to build on the strengths of ISE practices by placing an emphasis on the provision of hands-on practical and inspirational experiences. In developing programmes across a network of science centres, the project team also hoped to build capacity in the UK ISE field. 
The EYU programme was implemented by ten partner science and technology centres $^{2}$ and involved adults, families and visiting school groups. The public activities that made up the EYU programme included school activities (Workshops and Masterclasses for students), a family show, and 'Meet the Expert' events. In total, the national programme reached 122,546 students, teachers and members of the public. The majority of the participants attended the family show or Meet the Expert events, while 9,600 students attended the school Workshops, and 3,174 students attended the Masterclasses. Participating science centres were provided with a 40-page handbook; specialist equipment including a thermal imaging camera, solar telescope, and a particle accelerator 'in a salad bowl'; a two-day training course; and also support in meeting and developing collaborations with local scientists.

Evaluation design and methods
The evaluation of the EYU programme was carried out by a team of researchers who were uninvolved in the practical elements of the project design or its delivery. ${ }^{3}$ The evaluation was summative rather than formative and was commissioned by the project management team to examine teacher, student and public responses to the activities offered. In addition to public audiences, stakeholders who contributed professionally to the project, such as STFC scientists participating in the events, science centre staff involved in coordinating the events and ASDC staff managing the project were also surveyed or interviewed about their experiences of EYU.

The theoretical approach to the evaluation framed learning and engagement as a longitudinal processes, developed within and beyond experiences of the EYU programme [Lemke, 2000; Rahm and Ash, 2008; Roth and Van Eijck, 2010]. Given this, we did not attempt to measure students' science learning or attitude change as we recognised that we did not have the capacity to collect data over time and across multiple contexts. Instead, we designed the evaluation to explore programme specific expectations, experiences and reflections from a broad range of participants during the life of the project within project spaces. Whilst we recognise the limitations of such 'snapshot' style data collection, it is arguably more practical for a project of this sort. In developing the evaluation protocol, we proposed the use of questionnaires and more qualitative interview instruments. Separate questionnaires (with primarily closed questions, with some short answers) were developed for Workshop participants, Masterclass participants, and their respective teachers. More open-ended questionnaires were developed for science centre staff and participating scientists. Family visitors to the family shows and the Meet the Scientist events were surveyed via short (5 question) structured interviews, whilst funders and project team took part in longer semi-structured telephone interviews.

The evaluation was thus designed as a contextually grounded multi-site, multi-event case study [Stake, 1994]. In other words, the entire EYU programme was taken as the 'case' with the individual activities carried out across the 10 science centres understood as linked elements of the same case study. The evaluation followed a multiple methods approach, commonly used to provide

\footnotetext{
${ }^{2}$ The following science and technology centres participated in EYU: Winchester Science Centre (formerly Intech); Satrosphere Science Centre; Our Dynamic Earth; Catalyst Science Centre; Glasgow Science Centre; Science Oxford; The Observatory Science Centre; Dundee Science Centre; Royal Observatory Greenwich; and At-Bristol.

${ }^{3}$ Except Author 2, who supported two training sessions for scientists as part of this programme.
} 
investigative depth and analytic validity by exploring issues from more than one perspective [Bledsoe and Graham, 2005; Tashakkori and Teddlie, 2003].

Due to the scale of the project, staff from the participating science centres were involved in the data collection following protocols developed by the research team. Staff were thus trained to administer questionnaires to students and their teachers, and to also conduct short structured interviews with visitors attending the family shows and the Meet the Expert sessions. This distributed model of data collection was crucial for the project since it enabled the collection of a large amount of data with which to assess the outcomes of the nation-wide project. Involving science centre staff in this manner also provided institutions with immediate access to the raw data they collected and thus the opportunity to react to any practical feedback as they saw fit. The research team conducted the remaining elements of the evaluation, surveying scientists and science centre staff involved in the programme and carrying out semi-structured interviews with the project team. Table 1 lists the numbers of responses and a brief summary of data collection methods. The number of responses for students, teachers and visitors represents the combined totals collected by the ten participating science centres.

Categorical and attitudinal data from the Workshop and Masterclass questionnaires were transposed onto SPSS datasets. Descriptive statistics were generated for the key questionnaire items. As discussed earlier, the aim of the EYU programme was to inspire a new sense of excitement amongst young people about the physical sciences. In designing the questionnaire items, our proxy for 'a new sense of excitement' was the extent to which the students expressed an interest in science. In keeping with broader policy foci and wider concerns about numbers of young people entering science careers, the questionnaire also included items about the young people's inclinations towards science related careers.

Prior research has suggested that student perceptions with regards their interest in science and inclination towards a science-related career can change considerably between the ages of 10 and 16 [Archer et al., 2010; Lindahl, 2007]. For this reason, the datasets for the Workshop participants (targeted at ages 10-13) and the Masterclass participants (targeted at ages 14-16) were created and analysed separately.

However, despite the aim of collecting large and representative samples for each dataset, uncontrollable events such as schools bringing students older or younger than expected, and localized problems in collecting data, resulted in significantly unequal response rates between science centres and within school year groups. As such, valid inferential statistics between these variables were unattainable. To partly circumvent this limitation, we conducted Chi Square tests on the data examining the questionnaire items that gauged the affect of the EYU programme on participants' interest in a science education and career using the Masterclass and Workshop categories as grouping variables. In other words, because different science centres collected different amounts of data from different age groups of students, we grouped students analytically by the type of activity they participated in (Workshop or Masterclass), but acknowledge this was only a rough proxy for age. 
Table 1. EYU evaluation data collection methods and participants.

\begin{tabular}{|c|c|}
\hline Participants \& EYU activities & Method and data collected \\
\hline $\begin{array}{l}\text { 10-13 year old students in the } \\
\text { schools Workshop }(n=2,203)\end{array}$ & $\begin{array}{l}\text { Brief (12 item) questionnaire, completed on site immedi- } \\
\text { ately after participation in the workshop, comprising of } \\
\text { closed and open-ended items designed to capture stu- } \\
\text { dent participant views on the workshop, interest in sci- } \\
\text { ence education and science careers, and their percep- } \\
\text { tion of the differences between the workshop science } \\
\text { lessons and in from their schools. }\end{array}$ \\
\hline $\begin{array}{l}\text { 14-16 year old students in the } \\
\text { Masterclass }(n=1,680)\end{array}$ & $\begin{array}{l}\text { Brief (12 item) questionnaire completed on site immedi- } \\
\text { ately after participation in the Masterclass, comprising } \\
\text { of closed and open-ended items designed to capture } \\
\text { student participant views on the Masterclass, interest in } \\
\text { science education and science careers, and their percep- } \\
\text { tion of the differences between the Masterclass science } \\
\text { lessons and those in their schools. }\end{array}$ \\
\hline $\begin{array}{l}\text { Teachers of } 10-13 \text { year old stu- } \\
\text { dents in the Schools Workshop } \\
(\mathrm{n}=232)\end{array}$ & $\begin{array}{l}\text { Brief (14 item) questionnaire, completed on site imme- } \\
\text { diately after participation in the workshop compris- } \\
\text { ing closed and open-ended questions probing teachers } \\
\text { views about the Workshop }\end{array}$ \\
\hline $\begin{array}{l}\text { Teachers of } 14-16 \text { year old } \\
\text { students in the Masterclasses } \\
(\mathrm{n}=137)\end{array}$ & $\begin{array}{l}\text { Brief }(14 \text { item) questionnaire, completed on site imme- } \\
\text { diately after participation in the workshop compris- } \\
\text { ing closed and open-ended questions probing teachers } \\
\text { views about the Masterclass }\end{array}$ \\
\hline $\begin{array}{l}\text { Families attending the Family } \\
\text { Shows }(\mathrm{n}=327)\end{array}$ & $\begin{array}{l}3-5 \text { minutes long structured interview probing visitor re- } \\
\text { call, enjoyment, and understanding of science. }\end{array}$ \\
\hline $\begin{array}{l}\text { Science centre visitors attending } \\
\text { the Meet the Experts Events } \\
(\mathrm{n}=316)\end{array}$ & $\begin{array}{l}\text { 3-5 minutes long structured interview probing visitor re- } \\
\text { call, enjoyment, and understanding of science. }\end{array}$ \\
\hline $\begin{array}{l}\text { Scientists involved in the } \\
\text { training and delivery of EYU } \\
(\mathrm{n}=26)\end{array}$ & $\begin{array}{l}\text { Questionnaires completed by email comprising demo- } \\
\text { graphic questions and open-ended questions probing } \\
\text { the scientists' experiences and also attitudes to public } \\
\text { engagement more broadly. }\end{array}$ \\
\hline Science Centre Staff $(\mathrm{n}=19)$ & $\begin{array}{l}\text { Questionnaires completed by email with mostly open } \\
\text { questions asking staff about their perceptions of the } \\
\text { programme and its impact more broadly. }\end{array}$ \\
\hline Project team $(\mathrm{n}=5)$ & $\begin{array}{l}\text { Semi-structured interviews asking project stakeholders } \\
\text { about their perceptions of the programme and its im- } \\
\text { pact more broadly. }\end{array}$ \\
\hline
\end{tabular}

Open-ended questionnaire items examined students' perceptions of the differences between the activities in science centre-led Workshops and Masterclasses and typical lessons at school. Such questions were included to further probe the efficacy of the model underpinning the EYU programme, which asserts the value of science centres in fostering science engagement. Responses to these items were transposed onto NVivo datasets, and analysed via a mix of quantitative and qualitative content analyses methods. This consisted of generating initial thematic codes from word count frequencies and distributions, and then textually examining those codes for their connotative meanings. These methods have been consistently shown to generate valid and contextualised findings from large textual databases [Krippendorff, 2012], and in the context of our analysis, provided us with a form of methodological triangulation to validate our analyses. 
Data from the short structured interviews with family visitors that attended the family shows and Meet the Expert events, from the questionnaires (with open-ended questions only) given to the scientists, science centre staff and from the longer semi-structured interviews with the project team were analysed using a qualitative grounded theory approach. This consisted of identifying, classifying and crosschecking key themes present in the data [Lewis and Ritchie, 2003]. Then, following an initial mapping of the data and articulation of the key themes (represented by exemplar quotes), data were reviewed and recoded iteratively until two researchers (Authors $1 \& 2$ ) agreed with the categorisation [Miles and Huberman, 1994].

The full findings are reported in the final evaluation of the EYU project [King et al., 2014]. In the sections below, key findings are summarised and implications for the wider field are highlighted.

The EYU project sought to inspire young people in the physical sciences. Data from the aspects of EYU open to the general public (the family shows and the Meet the Expert events) suggest that EYU met this aim: all 646 responses to the short interview questions were positive with many of the general public visitors describing the events as "interesting" or "inspiring". However, a word of caution is perhaps necessary here. As several authors have previously noted, audiences voluntarily attending informal science education institutions and events are self-selecting and tend to have pre-existing positive attitudes towards such experiences [Hornig Priest, 2009; Packer, 2008; Rennie and Williams, 2006; Wellcome Trust, 2008; Wilkinson, Dawson and Bultitude, 2012].

The contingent nature of self-selected participants notwithstanding, the value of attending such events and engaging in face-to-face interactions with scientists should not be underestimated. Indeed, comments such as "I would like to be a scientist when I grow up because they do lots of different things and it sounds exciting" and "they [scientists] just seem like ordinary people but are younger than I thought they would be: I thought all scientists were old - like my parents" voiced by young people attending the family events, underscore the value of such encounters for challenging stereotypes and addressing gaps in understanding about the nature of scientific careers. In addition, the face-to-face interactions between the scientists and visitors appeared to be key in helping visitors establish a personal connection with abstract concepts. As one young respondent from a Meet the Expert event put it "I like that I shook hands with a scientist who studies really far away galaxies."

Similarly positive responses were observed in the students who attended the Workshop and Masterclasses. For example, 79.1\% of the Workshop respondents reported that they would recommend the activity to others, $16.6 \%$ were not sure, and only $3.5 \%$ would not recommend it. Correspondingly, $83.8 \%$ of the Masterclass respondents reported that they would recommend this class to others, $13.6 \%$ were not sure, and only $2.5 \%$ said that they would not recommend it. Additionally, responses to the questionnaire items listed in Tables 2 and 3 suggest that both of the sessions were successful in making science appealing to participants. 
Table 2. Student responses to the questionnaire item probing intentions for future study: Did the activity today make you feel...

\begin{tabular}{|l|c|c|}
\cline { 2 - 3 } \multicolumn{1}{c|}{} & Workshop $(\mathrm{n}=1581)$ & Masterclass $(\mathrm{n}=1588)$ \\
\hline Response Categories & $\%$ & $\%$ \\
\hline More interested in studying science & 55.0 & 43.1 \\
\hline $\begin{array}{l}\text { The same, I already knew that I wanted } \\
\text { to study science }\end{array}$ & 20.1 & 34.8 \\
\hline $\begin{array}{l}\text { The same I already knew that I didn't } \\
\text { want to study science }\end{array}$ & 13.4 & 15.7 \\
\hline Less interested in studying science & 2.8 & 1.7 \\
\hline Missing & 8.7 & 4.7 \\
\hline
\end{tabular}

Table 3. Student responses to the questionnaire item probing future career intentions: Did the activity today make you feel...

\begin{tabular}{|c|c|c|}
\hline & $\begin{array}{l}\text { Workshop }(\mathrm{n}=1581) \\
\text { Ages } 10-13\end{array}$ & $\begin{array}{c}\text { Masterclass }(\mathrm{n}=1588) \\
\text { Ages 14-16 }\end{array}$ \\
\hline Response Categories & $\%$ & $\%$ \\
\hline $\begin{array}{l}\text { I am more likely to consider a career in } \\
\text { science }\end{array}$ & 40.7 & 37.0 \\
\hline $\begin{array}{l}\text { I already knew that I wanted to work in } \\
\text { science }\end{array}$ & 12.8 & 19.5 \\
\hline $\begin{array}{l}\text { I already knew that I didn't want to work } \\
\text { in science }\end{array}$ & 29.0 & 35.5 \\
\hline $\begin{array}{l}\text { I am less likely to consider a career in } \\
\text { science }\end{array}$ & 7.9 & 3.9 \\
\hline Missing & 9.6 & 5.1 \\
\hline
\end{tabular}

The figures reported in Tables 2 and 3 indicate EYU's mostly positive influence on students' self-reported interest in science education and intent to pursue to a science-related career. However, it is acknowledged that the figure of $7.9 \%$ of the Workshop students responding that they were less likely to consider a science career after their EYU experiences is far from ideal In addition, the relatively high percentages of students - 29.0\% of Workshop and 34.5\% of Masterclass respondents - who reported that they already knew they did not want a career in science is somewhat intriguing A possible interpretation here is that EYU and similar programmes designed to encourage students to pursue science careers may be effective at supporting students who are already inclined towards science, but offer less in the way of impact to those already inclined away from science. At this point a limitation in the data capture should be acknowledged: schools were not routinely asked about the criteria on which they had selected children for attending the activities. Anecdotal feedback would suggest that some school groups comprised students selected on the basis of being more able and interested in science, whilst other groups comprised less engaged students whom teachers were keen to inspire. For future evaluations we have advised the inclusion of an additional item on the teacher questionnaires asking for specification of the group's typical interests and aspirations in science. Moreover, we note that in order to make a more substantiated interpretation of the data, more detailed teasing out of the students' prior experiences and perceptions of science would have been useful. Unfortunately, in depth interviews with students were not possible given the scope of the evaluation. 
Another finding of particular interest it that the Workshop participants, comprising the younger age group, had more positive responses to these questions than the older participants from the Masterclass cohort. A Chi square test showed that these differences were statistically significant for both the data corresponding to Table 2 $\chi^{2}(3, N=2956)=90.157 \mathrm{p}=.000$ and Table $3 \chi^{2}(3, N=2937)=52.251 \mathrm{p}=.000$. Such findings may be of interest to those querying the age range at which an initiative is likely to have the most effect. For example, it could be argued that older students need more support. Alternatively, one could predict that efforts may be more fruitful if directed towards the more enthusiastic younger populations. This issue is discussed further below.

In examining the key features of the Workshop and Masterclass programmes that prompted positive feedback, the data would suggest that the aspects of novelty and hands-on learning were important. For example, responses to questions that probed the use of equipment and delivery style, and more directly, asked respondents to compare their school and science centre experiences, indicate a tangible difference in students' perceptions. Students cited the EYU programme as affording a greater opportunity to conduct experiments, greater interactivity, and the chance to engage with unique equipment and materials. As one Masterclass student put it "At school we don't have asteroids". Interestingly, many teachers attending the sessions commented that they used similar experiments and interactive approaches in their classrooms. Nonetheless, their students clearly perceived there to be a difference, particularly around the use of equipment, with only $4.0 \%$ of Workshop students and $2.6 \%$ of Masterclass students claiming they often used equipment similar to that in the EYU programme in their schools. In other words, the vast majority of students were unfamiliar with the materials and equipment they encountered in the EYU project.

In reviewing the findings presented above, and in reflecting on their implications, a caveat is necessary. While the responses arguably support calls for more science engagement initiatives of this type, a more critical reading would query the reliability of self-reported data [Donaldson and Grant-Vallone, 2002]. Given the distributed model of data collection, it is also possible that in being asking to complete evaluations by science centre staff, the respondents replied more positively than had an independent evaluator been present. It is also important to note that students' views captured immediately after a novel and interactive learning experience shed little light on the nature of their views a week, a month or a year later. These limitations notwithstanding, further analyses of the data, and in particular the responses to the open-ended questions, offer a series of findings that inform the design and direction of programmes similar to EYU, but may also constitute useful considerations for the wider field. We outline these findings below.

\subsection{The effect of age}

As outlined above, the student data were analysed to look for differences in responses by age group (with Workshops targeted at 10-13 year olds and Masterclasses at 14-16 year olds). The aim here was to determine whether there is an age group in which opinions are framed more positively, or more negatively, and indeed at which age interventions may be best targeted. As stated earlier, 
inferential statistics for comparisons by school year were unattainable due to significantly uneven sample sizes. However, although we acknowledge the age ranges used analytically are a proxy, the broad findings indicate a greater positivity amongst the younger student group

This finding complements other studies which suggest that interventions targeted at influencing the views and attitudes of students as young as 10 may be just as, if not more, efficacious as those targeting secondary age students Indeed, as Maltese and Tai [2010] found in a series of interviews with scientists and graduate students, $65 \%$ of respondents reported their interest in science to have begun before reaching middle school (age 11). Salehjee and Watts [2015], meanwhile, in their study examining science and non-science career choices note that many of the respondents' life stories were effectively set by age 8 . Similarly, findings from a questionnaire conducted for the Royal Society [OPM, 2006] found that children's experiences prior to age 14 are a major determinant of any decision to pursue science, while a number of studies have shown aspirations to work in the sciences are largely formed by the age of 13 [Lindahl, 2007; Archer et al., 2012; Archer et al., 2013].

Taken together, therefore, these studies along with the EYU evaluation findings suggest that age is a significant factor in determining the success of physics and ISE activities that hope to recruit students to physics. Furthermore, these findings suggest that science careers engagement programmes may wish to consider targeting students between the ages of 10 and 14, rather than focusing solely on older students, as by then, it may be too late to change minds (see for example, the data in Table 3).

\subsection{The effect of gender}

In terms of gender attendance at both the Workshop and Masterclass was evenly mixed across the whole data set, with the gender breakdown for the Workshop being $49 \%$ female, $51 \%$ male, and the gender breakdown for the Masterclass being $54.6 \%$ female, $45.3 \%$ male (two students did not answer). In analysing the responses, we found no statistically significant quantitative or qualitative differences in the types of responses by gender for either the Workshop or Masterclass. In other words, we found that participating in the EYU programme did not appear to disadvantage, put-off or otherwise negatively affect the female or the male students. This finding contrasts with research on girls' perceptions of science which has found that girls enjoy science less and hold fewer aspirations towards science careers than their male peers [Vetleseter Boe et al., 2011]. So how may this contrast between the EYU findings and established patterns within the science education literature be explained? There are several possible answers. For example, there may have been something about the design of EYU activities that appealed to both girls and boys. Indeed, studies have found that exposure to an array of experiences, such as those offered by the EYU programme, can help students develop a greater self concept for science [Buccheri, Gürber and Brühwiler, 2011] which in turn enhances their enjoyment and perception of themselves engaging in a science-related career in the future. Tan et al. [2013], meanwhile, found that girls used out of school experiences to add meaning and context to the science they were learning in school, and began to see science as something that could be part of their possible futures. In addition, it is possible that 
the emphasis on the utility of science and application of the physical sciences that was a feature of both the Workshop and the Masterclass may have provided girls with a greater understanding of the broad nature of science-related careers and in turn prompted more positive responses.

It is of course also possible that the questionnaire tools used for this evaluation were not sufficiently fine-grained to pick up significant differences. Further observational research of EYU events and interviews would be useful to unpick the gendered (as well as classed and ethnic) dimensions of participation. Indeed, this finding, when compared to the broader field of research, suggests we need to continue to pay careful attention to gender issues in physics and ISE (as well as how gender intersects with the axes of class, ethnicity, ability/disability, sexuality and so on).

\subsection{The effect of emphasising the 'real world' nature of science careers}

In reviewing student responses to the open-ended questionnaire items, two related themes were prevalent. The first can be described as the appeal of the 'real-world' or contemporary nature of the science being presented. For example, Masterclass students commented on being excited by science that "is being worked on right now". Secondly, students welcomed the opportunity to learn first-hand about what a physics career might involve. A typical Masterclass student comment was "it's good to know the situation before considering studying it."

Teachers similarly appreciated the real world framing of the sessions, noting that the activities "made some aspects [of physics] seem more relevant and applicable", and that activities would help "students realise that science is a lot more vast than the classroom." Teachers also valued the information about science careers that was an inherent feature of the sessions: one teacher noted that the experience was invaluable for allowing students to "envisage their career paths when they know what others are doing with physics." Clearly, hand-on programmes with practising scientists can play a key role in showcasing the real-world nature of scientific careers to broad audiences. These findings echo findings elsewhere in the literature [Van Eijck, 2007; Carlone et al., 2015] that point to the importance of engagement with 'real' phenomena, artifacts and scientific practitioners for supporting science learning and developing aspirations to pursue science-related careers.

\subsection{The important role of novelty}

As noted above, a key factor affecting the positive response to the Workshop and Masterclass activities, and indeed a theme present in the data from the family shows and Meet the Expert events can be described as the novelty of the experience. Dohn [2011] has suggested that the novel learning environments may help to trigger situational interest, which in turn may lead to deeper and more sustained personal interest in a topic. In addition, the novelty of expertise provided in the form of the presenters, and participating scientists, should not be underestimated. As one teacher noted "other specialists make things more memorable."

While marketing departments in science centres have long welcomed novel and memorable experiences for prompting return visits, the significance of such 
experiences for learning more broadly are now being recognised. For example, researchers have recently begun to conceptualise learning as occurring across a rich ecology of different, and complementary and competitive activities linking both informal and formal providers [Falk et al., 2012; Stocklmayer, Rennie and Gilbert, 2010; Russell, Knutson and Crowley, 2013]. From this perspective events that are particularly memorable provide a central point of reference onto which other related activities, such as those in the classroom or the home, may hook. As Hidi and Renninger [2006] argue in their model of interest development, situational interest is only the first of four phases of interest development. As such, then, we suggest that while novelty may indeed work well as a 'hook' it is also important for those involved in engagement activities, such as EYU, to continue their efforts beyond a reliance on novelty.

\subsection{The value of collaboration}

Stakeholders across the project recognised their participation in EYU as building capacity in their institutions. In particular, respondents welcomed the development of collaborative relationships between different institutions such as science centre and school, or science centre and site of physics research. Several scientists, for example, welcomed the expertise and environment provided by the science centres and their staff. One commented on how science centres provided a "ready made audience for science outreach" while another suggested that working with science centres provided "access to resources you might not otherwise have."

All the science centre staff respondents commented on their increased institutional capacity. Alongside acknowledgement of benefits that might be expected - more knowledgeable staff, new workshop ideas and new equipment - respondents emphasised the value of new networks and collaborative working with other science centres, for example stating "I feel that this project strengthened our relationship and has made collaborative working in the future even more likely." Furthermore, they welcomed being the intermediaries between schools and the professional practice of scientific research. As one science centre staff member put it: "having direct links with experts and teachers is a valuable way of maintaining scientific integrity in our projects."

\subsection{The impact of engagement on participating scientists}

Science centre staff also noted gains in their personal capacity and cited the acquisition of new skills in audience targeting, marketing and planning. Such skills are understandably valuable to such staff linked as they are to day-to-day work and, potentially, career progression. In contrast, several of the participating scientists highlighted a disconnection between their engagement in EYU and their career advancement. Several noted that public engagement activities take time away from research and that the latter is favoured more highly by managers: "I have found that my current university does not value public engagement and science communication... it is also viewed as a 'lesser' skill to 'research."' When viewing their participation as a personal investment, however, most of the scientists vigorously welcomed the EYU programme, often citing an altruistic desire to support the public's physics learning experiences. 
That scientists emphasised their personal enjoyment over and above potential benefits to their careers can be understood in relation to the career positions of those who participated. Demographic data collected from the participating scientists shows that more 'junior' scientists — PhD students and early career researchers participated than 'senior' scientists. Indeed, one senior academic surveyed as part of the EYU evaluation said that she had had "too many other commitments" to participate in public engagement prior to this project. This finding is particularly interesting when compared with prior research about scientist involvement in ISE and public engagement activities. Bauer and Jensen [2011], for example, found that most engagement patterns were quite the reverse, with public engagement practices generally being dominated by senior professors rather than junior staff.

In seeking to explain the patterns of participation we uncovered in our evaluation, one reason could be that participation in the EYU programme did not align with the scientists' institutional assessment frameworks for public engagement. If this is the case (and further research is necessary to be certain) ISE programme developers may need to pay more attention to the needs of the scientists they wish to recruit, and work around the scientists' institutional priorities accordingly. This recommendation concurs with and builds on the work of Burchell, Franklin and Holden [2009] and Davies [2008] who have argued that institutional requirements and assessments must be better aligned with the nature of public engagement practices if the wider field is to fully realise its desire of increasing recruitment.

The evaluation findings summarised above indicate that the EYU programme was successful in meeting its aim of inspiring young people with a sense of excitement for the physical sciences. The depth and duration of this inspiration, however, is less easy to call. As discussed above, the evaluation represents a snapshot of views and cannot speak to the notion of 'impact' beyond the window of time in which data were collected. Moreover, the lack of any pre-testing of respondents means that it was impossible to measure any change in individuals' views before and after their participation in EYU. Nonetheless, the evaluation has provided a useful body of knowledge for the EYU stakeholders and recommendations in the evaluation report have informed the design of Phase Two of the EYU programme (which began in 2014). But more importantly, perhaps, the evaluation also served to identify several significant issues for the wider field. These include a challenge to the common perception that girls are intrinsically less interested in science and suggestions - which need further investigation - about the nature of programmatic elements that appear to appeal more to girls, or to boys. The findings also add weight to emerging thinking around the best age at which to begin careers information. The data show that children as young as 10 are thoughtful about their futures, and may already be forming strong opinions. Indeed one might say that science engagement initiatives that support and target primary age students would not be wasting their time.

The value of collaborations between science centres and schools is another key finding. The informal science sector is arguably well placed to act as an intermediary between scientists and schools. Moreover, teachers clearly recognise and welcome the support that science centres can provide particularly with regards to providing resources or providing information about science-related careers. 
A further issue from the evaluation findings raises questions about the ways in which institutions support and condone the efforts of individual scientists in public engagement initiatives. The evident mismatch between the national aim of recruiting more physical scientists and the limiting structures of many institutions preventing individuals undertaking recruitment work needs to be addressed.

In reviewing the data, it is also important to note that the design of the evaluation protocol itself was not without its limitations or deficiencies. The distributed data collection model worked well in terms of collecting a large body of questionnaire data, but the limited capacity of the science centre staff meant that more detailed and in depth qualitative, and location-specific, interviews with teachers or students were not feasible. Or course, it is always difficult to strike the right balance between depth of analysis and breadth of data set. In this instance, the project directors and funders were keen to collect a large data set that represented the efforts of project partners across the nation. In examining the data, many lessons have been learnt including the design of questionnaire instruments and the value of follow-up interviews. These lessons form our advice to the EYU team with regards future programme evaluations.

By sharing our findings and reflecting on our data in the light of recent research, we hope to have highlighted the value of evaluation studies that situate findings in the context of previous work and with due reference to theory. We also hope that our discussions and insights shared here will contribute to on going conversations around the nature and benefits of engagement activities in the ISE sector and beyond that aim to support young people's enjoyment of and participation in the physical sciences.

\section{References}

Anderson, D. and Nashon, S. (2007). 'Predators of knowledge construction: Interpreting students' metacognition in an amusement park physics program'. Science Education 91 (2), pp. 298-320.

Archer, L., DeWitt, J., Osborne, J., Dillon, J., Willis, B. and Wong, B (2010). “"Doing” science versus "being" a scientist: Examining 10/11-year-old schoolchildren's construction of science through the lens of identity'. Science Education 94 (4), pp. 617-639.

- (2012). 'Balancing acts": Elementary school girls' negotiations of femininity, achievement and science'. Science Education 96 (6), pp. 967-989.

- (2013). 'Not Girly, not sexy, not glamorous: Primary school girls' and parents' constructions of science aspirations'. Pedagogy, Culture E Society 21 (1), pp. 171-194.

Aroca, S. C. and Silva, C. C. (2011). 'Teaching astronomy in an informal space: observing the Sun and its sunspots'. Revista Brasileira De Ensino De Fisica 33 (1). DOI: $10.1590 / \mathrm{S} 1806-11172011000100013$.

Babcock Research (2011). Evaluation of the Stimulating Phyics Network. London, U.K.: Institute of Physics.

Bamberger, Y. and Tal, T. (2008). 'An Experience for the Lifelong Journey: The Long-Term Effect of a Class Visit to a Science Center'. Visitor Studies 11 (2), pp. 198-212.

Bauer, M. and Jensen, P. (2011). 'The mobilization of scientists for public engagement'. Public Understanding of Science 20 (1), pp. 3-11. 
Bell, P., Lewenstein, B., Shouse, A. W. and Feder, M. A. (2009). Learning science in informal environments: People, places and pursuits. Washington D.C., U.S.A.: The National Academies Press.

Bledsoe, K. L. and Graham, J. A. (2005). 'The Use of Multiple Evaluation Approaches in Program Evaluation'. American Journal of Evaluation 26 (3), pp. 302-319.

Brandon, P. R. and Fukunaga, L. L. (2014). 'The State of the Empirical Research Literature on Stakeholder Involvement in Program Evaluation'. American Journal of Evaluation 35 (1), pp. 26-44.

Buccheri, G., Gürber, N. and Brühwiler, C. (2011). 'The impact of gender on interest in science topics and the choice of scientific and technical vocations'. International Journal of Science Education 33 (1), pp. 159-178.

Burchell, K., Franklin, S. and Holden, K. (2009). Public culture as professional science. Final report of the ScoPE project. London, U.K.: London School of Economics.

Carlone, H. B., Huffling, L. D., Tomasek, T., Hegedus, T. A., Matthews, C. A., Allen, M. H. and Ash, M. C. (2015). "Unthinkable' Selves; Identity boundary work in a summer field ecology enrichment program for diverse youth'. International Journal of Science Education 37 (10), pp. 1524-1546.

Carpineti, M., Cavallini, G., Giliberti, M., Ludwig, N., Mazza, C. and Perini, L. (2006). "'Let's throw light on matter": A physics show for primary school'. Nuovo Cimento Della Societa Italiana Di Fisica B-General Physics Relativity Astronomy and Mathematical Physics and Methods 121 (8), pp. 901-911.

Davies, S. (2008). 'Constructing communication: Talking to scientists about talking to the public'. Science Communication 29 (4), pp. 413-434.

Dewitt, J. and Hohenstein, J. (2010). 'Supporting Student Learning: A Comparison of Student Discussion in Museums and Classrooms'. Visitor Studies 13 (1), pp. 41-66. DOI: 10.1080/10645571003618758.

Dohn, N. B. (2011). 'Situational interest of high school student who visit an aquarium'. Science Education 95 (2), pp. 337-357.

Donaldson, S. I. and Grant-Vallone, E. J. (2002). 'Understanding self-report bias in organizational behaviour research'. Journal of Business and Psychology 17 (2), pp. $245-260$.

Eratuuli, M. and Sneider, C. (1990). 'The Experiences of Visitors in a Physics Discovery Room'. Science Education 74 (4), pp. 481-493.

Falk, J. H., Osborne, J., Dierking, L. D., Dawson, E., Wenger, M. and Wong, B. (2012). Analyzing the UK Science Education Community: The contribution of informal providers. London, U.K.: Wellcome Trust.

GIREP (2002). 'Physics on Stage: buzzing around the tulips'. Physics Education 37 (3).

Hein, G. (1994). 'Evaluation of museum programme and exhibits'. In: The educational role of the museum. Ed. by E. Hooper Greenhill. London and New York: Routledge, pp. 306-312.

Hidi, S. and Renninger, K. A. (2006). 'The four-phase model of interest development'. Educational Psychologist 41 (2), pp. 111-127.

Hornig Priest, S. (2009). 'Reinterpreting the audience for media messages about science'. In: Investigating science communication in the information age. Ed. by R. Holliman, E. Whitelegg, E. Scanlon, S. Smidt and J. Thomas. Oxford and New York: Oxford University Press, pp. 224-236.

Institute of Physics (2014). Raising Aspirations in Physics: A review of research into barriers to STEM participation for students from disadvantaged backgrounds. URL: http://www.iop.org/publications/iop/2014/file_64466.pdf. 
Joint Council for Qualifications (2014). A, AS and AEA Results, Summer 2014. URL: http://www.jcq.org.uk/examination-results/a-levels/2014/a-as-andaea-results-summer-2014.

King, H., Dillon, J., Dawson, E. and Osborne, C. (2014). Explore Your Universe. Final Evaluation Report. London, U.K.: King's College London.

King, H., Steiner, K., Hobson, M., Robinson, A. and Clipson, H. (2015). 'Highlighting the value of evidence-based evaluation: pushing back on demands for 'impact'. JCOM 14 (02), A02. URL: http://jcom.sissa.it/archive/14/02/JC0M_1402_2015_A02.

Krippendorff, K. (2012). Content Analysis: An Introduction To Its Methodology. Beverly Hills, CA, U.S.A.: Sage.

Lemke, J. L. (2000). 'Across the scales of time: Artifacts, activities and meanings in ecosocial systems'. Mind, Culture and Activity 7 (4), pp. 273-290.

Lewis, J. and Ritchie, J. (2003). 'Generalising from qualitative research'. In: Qualitative research practice: A guide for Social Science students and researchers. Ed. by J. Ritchie and J. Lewis. Los Angeles, London, New Delhi and Singapore: Sage, pp. 263-286.

Lindahl, B. (2007). 'A longitudinal study of students attitudes toward science and choice of career'. Paper presented at the $80^{\text {th }}$ NARST International Conference, New Orleans, LA, U.S.A.

Lloyd, R., Neilson, R., King, S. and Dyball, M. (2012). Review of Informal Science Learning. London, U.K.: Wellcome Trust.

Luke, J. J. and McCreedy, D. (2012). 'Breaking Down Barriers: Museum as Broker of Home/School Collaboration'. Visitor Studies 15 (1), pp. 98-113.

Maltese, A. V. and Tai, R. H. (2010). 'Eyeballs in the fridge: sources of early interest in science'. International Journal of Science Education 32 (5), pp. 669-685.

Miles, M. B. and Huberman, A. M. (1994). Qualitative data analysis. 2nd ed. London, Thousand Oaks, New Delhi: Sage.

Morris, C. (1990). 'Importing "Hands-on" Science into Schools: The Light Works Van Programme'. Physics Education 25 (5), pp. 263-266.

Moussouri, T. and Roussos, G. (2013). 'Examining the Effect of Visitor Motivation on Observed Visit Strategies Using Mobile Computer Technologies'. Visitor Studies 16 (1), pp. 21-38.

National Science Foundation (2012). Science and Engineering Indicators 2012. URL: http://www.nsf.gov/statistics/seind12/.

Nielsen, W. S., Nashon, S. and Anderson, D. (2009). 'Metacognitive Engagement during Field-Trip Experiences: A Case Study of Students in an Amusement Park Physics Program'. Journal of Research in Science Teaching 46 (3), pp. 265-288.

Nurse Rainbolt, G., Benfield, J. A. and Loomis, R. J. (2012). 'Visitor Self-Report Behavior Mapping as a Tool for Recording Exhibition Circulation'. Visitor Studies 15 (2), pp. 203-216.

OPM, for the Royal Society (2006). Taking a leading role — Scientists questionnaire. London, U.K.: The Royal Society.

Osborne, J. and Collins, S. (2000). Pupils' and parents' views of the school science curriculum. London, U.K.: King's College London.

Packer, J. (2008). 'Beyond learning: Exploring visitors' perceptions of the value and benefits of museum experiences'. Curator: The Museum Journal 51 (1), pp. 33-54.

Phipps, M. (2010). 'Research Trends and Findings From a Decade (1997-2007) of Research on Informal Science Education and Free-Choice Science Learning'. Visitor Studies 13 (1), pp. 3-22. 
Rahm, J. and Ash, D. (2008). 'Learning environments at the margin: Case studies of disenfranchised youth doing science in an aquarium and an after-school program'. Learning Environments Research 11 (1), pp. 49-62.

Reichborn-Kjennerud, K. (2014). 'Performance audit and the importance of the public debate'. Evaluation, pp. 368-385.

Rennie, L. J. and Williams, G. F. (2006). 'Adults' learning about science in free-choice settings'. International Journal of Science Education 28 (8), pp. 871-893.

Roth, W.-M. and Van Eijck, M. (2010). 'Fullness of life as a minimal unit: Science, technology, engineering and mathematics (STEM) learning across the life span'. Science Education 94 (6), pp. 1027-1048.

Russell, J., Knutson, K. and Crowley, K. (2013). 'Informal learning organizations as part of an educational ecology: Lessons from collaboration across the formal/informal divide'. Journal of Educational Change 14 (3), pp. 259-281.

Salehjee, S. and Watts, M. (2015). 'Science Lives; School choices and 'natural tendencies". International Journal of Science Education 37 (4), pp. 727-743.

Sanchez-Mora, M. C. (2014). 'Evolution of evaluation in science museums and centres'. JCOM 13 (01), C02. URL: http://jcom.sissa.it/archive/13/01/JCOM_1301_2014_C02.

Smith, E. (2010). 'Do we need more scientists? A long-term view of patterns of participation in UK undergraduate science programmes'. Cambridge Journal of Education 40 (3), pp. 281-298.

Stake, R. (1994). The art of case study research. London, Thousand Oaks and New Delhi: Sage.

Stocklmayer, S., Rennie, L. and Gilbert, J. K. (2010). 'The roles of the formal and informal sectors in the provision of effective science education'. Studies in Science Education 46 (1), pp. 1-44.

Storksdieck, M., Haley-Goldman, K. and Jones, M. C. (2002). Impact of the New York Hall of Science Career Ladder Program on its former participants. Annapolis, MD, U.S.A.: Institute for Learning Innovation.

Tan, E., Calabrese Barton, A., Kang, H. and O'Neill, T. (2013). 'Desiring a career in Stem-related fields: How middle school girls articulate and negotiate identities-in-practice in science'. Journal of Research in Science Teaching 50 (10), pp. 1143-1179.

Tashakkori, A. and Teddlie, C. (2003). 'Major issues and controversies in the use of mixed methods in the Social and Behavioural Sciences'. In: Handbook of mixed methods research in Social and Behavioural Research. Ed. by A. Tashakkori and C. Teddlie. London, Thousand Oaks and New Delhi: Sage, pp. 3-50.

The UK Association for Science and Discovery Centres (2011). From Quarks to the Cosmos. Bristol, U.K.: The UK Association of Science and Technology Centres.

Ulriksen, L., Madsen, L. M. and Holmegaard, H. T. (2010). 'What do we know about explanations for drop out/opt out among young people from STM higher education programmes?' Studies in Science Education 46 (2), pp. 209-244.

Van Eijck, M. W. (2007). 'Towards authentic forms of knowledge'. Cultural Studies of Science Educaiton 2, pp. 606-613.

Vetleseter Boe, M., Henriksen, E. K., Lyons, T. and Schreiner, C. (2011). 'Participation in science and technology: Young people's acheivement-related choices in late-modern societies'. Studies in Science Education 47 (1), pp. 37-72.

Wellcome Trust (2008). Millennium science centres impact assessment report. Executive summary. London, U.K.: Wellcome Trust. 
Wilkinson, C., Dawson, E. and Bultitude, K. (2012). "Younger people have like more of an imagination, no offence': Participant perspectives on public engagement'. International Journal of Science Education. Part B 2 (1), pp. 43-61. DOI: $10.1080 / 21548455.2011 .628503$.

Woolhouse, C. and Cochrane, M. (2010). “Now I think of myself as a physics teacher': negotiating professional development and shifts in self-identity'. Reflective Practice 11 (5), pp. 607-618.

Yalowitz, S., Garibay, C., Renner, N. and Plaza, C. (2013). Bilingual Exhibit Research Initiative: Institutional and intergenerational experiences with bilingual exhibitions. Washington D.C., U.S.A.: Center for Advancement of Informal Science Education.

Authors

Heather King is a Research Fellow at King's College London. Her work involves studying education programmes and initiatives based in museums and science centres both in the UK and internationally. E-mail: heather.1.king@kcl.ac.uk.

Emily Dawson is a Lecturer in Science Communication at UCL. Her work focuses on how people engage with and learn about science, with an emphasis on equity. E-mail: emily.dawson@ucl.ac.uk.

Rodolfo Leyva is a lecturer in sociology and criminology at Middlesex University. His work focuses on developing quantitative and experimental methods to explore the affects of social media on young people's political cognitive dispositions and practices. E-mail: r.leyva@mdx.ac.uk.

\section{How to cite}

King, H., Dawson, E. and Leyva, R. (2015). 'Highlighting the wider relevance of science centre evaluations: a reflection on the evaluation of a physics engagement programme'. JCOM 14 (04), A01. 